\title{
Profound Amnesia After Damage to the Medial Temporal Lobe: A Neuroanatomical and Neuropsychological Profile of Patient E. P.
}

\author{
Lisa Stefanacci, ${ }^{1}$ Elizabeth A. Buffalo, ${ }^{2}$ Heike Schmolck, ${ }^{1}$ and Larry R. Squire ${ }^{1,2,3,4}$ \\ Departments of ${ }^{1}$ Psychiatry, ${ }^{2}$ Neurosciences, and ${ }^{3}$ Department of Psychology, University of California, La Jolla, California \\ 92093, and 4 Veterans Affairs Medical Center, San Diego, California 92161
}

E. P. became profoundly amnesic in 1992 after viral encephalitis, which damaged his medial temporal lobe bilaterally. Because of the rarity of such patients, we have performed a detailed neuroanatomical analysis of E. P.'s lesion using magnetic resonance imaging, and we have assessed his cognitive abilities with a wide range of neuropsychological tests. Finally, we have compared and contrasted the findings for E. P. with the noted amnesic patient H.M, whose surgical lesion is strikingly similar to E. P.'s lesion.

Key words: memory; hippocampus; amnesia; E. P.; medial temporal lobe; encephalitis
In the earliest collected case reports of human memory impairment (Winslow, 1861; Ribot, 1881), it was recognized that the study of memory disorders can provide valuable insights into the structure and organization of normal memory. During the past 100 years, cumulative study of groups of amnesic patients and a few notable single cases have repeatedly illustrated this principle (Rapaport, 1942; Scoville and Milner, 1957; Talland, 1965; Butters and Cermak, 1980; Mayes, 1988; Baddeley et al., 1995).

The best known and most thoroughly studied case of human amnesia is patient H. M. (Scoville and Milner, 1957), who in 1953 sustained a bilateral resection of the medial temporal lobe in an effort to relieve severe epilepsy. More recently, the surgical lesion was described in considerable detail using magnetic resonance imaging (MRI) (Corkin et al., 1997). Comprehensive study of this patient over the years established the fundamental principle that the ability to acquire new memories is a distinct cerebral function, separable from other perceptual and cognitive abilities (Milner et al., 1998).

Most amnesic patients who have been available for study are less impaired than H. M., because their damage is less extensive than his. Nevertheless, a few very severely impaired patients have been described in the neuropsychological literature. Each of these patients became amnesic after an episode of viral encephalitis (patient S. S., Cermak, 1976; patient D. R. B., Damasio et al., 1985; and patient R. F. R., Warrington and McCarthy, 1988). However, in these cases, either no anatomical information is available about the patient or extensive damage has occurred outside the medial temporal lobe, and cognitive functions in addition to memory are impaired.

We here present neuroanatomical and neuropsychological findings for patient E. P. Patient E. P. became profoundly amnesic in 1992 after viral encephalitis, which damaged his medial temporal lobe bilaterally. After H. M., he is the only profoundly amnesic patient known to us for whom detailed neuroanatomical and neu-

\section{Received May 5, 2000; revised June 19, 2000; accepted June 26, 2000.}

This research was supported by the National Institute of Mental Health (NIMH) (5 T32 MH18399, MH24600, and 2T32AG00216), the Medical Research Service of the Department of Veterans Affairs, the McDonnell-Pew Center for Cognitive Neuroscience at San Diego, the National Alliance for Research on Schizophrenia and Depression, and the Metropolitan Life Foundation. E.A.B. is now at the Laboratory of Neuropsychology, NIMH (Bethesda, MD). We thank D. Amaral, D. Delis, J. Frascino, J. Hodges, T. Jernigan, M. Kritchevsky, C. F. Notestine, G. Press, C. Stark, S. Zola, and J. Zouzounis for assistance, and S. Corkin and E. Kensinger for discussions about patient H. M.

Correspondence should be addressed to Larry Squire, Department of Psychiatry, 0603, University of California at San Diego, La Jolla, CA 92093. E-mail: lsquire@ucsd.edu.

Copyright (C) 2000 Society for Neuroscience $0270-6474 / 00 / 207024-13 \$ 15.00 / 0$ ropsychological information is available and for whom damage is limited primarily to the medial aspect of the temporal lobe, bilaterally (Fig. 1). We have performed a qualitative and quantitative analysis of E. P.'s brain lesions using MRI, and we have assessed his cognitive abilities with a wide range of neuropsychological tests. Finally, we have compared and contrasted the findings for E. P. with the considerable body of information available for patient H. M.

\section{MATERIALS AND METHODS}

\section{Case history}

Patient E. P. is a right-handed male who was born in 1922 and grew up in a central California agricultural community. He has 12 years of education. From 1941 to 1950 , he traveled at sea as a radio operator for an oil company. Afterward, he lived in Los Angeles County, working for 28 years as a technician in the aerospace industry, then for 5 years as a part-time consultant. In 1993 he moved to San Diego County. E. P. has been married since 1950, and he currently lives at home with his wife. He has two grown children.

In November of 1992, at the age of 70, E. P. was diagnosed with herpes simplex encephalitis. His illness began with flu-like symptoms (fever and lethargy) and an episode of memory loss (he could not remember the names of some family members), which appeared to recover for a few days. However, his memory then worsened, and he was admitted to the hospital, where he received a $10 \mathrm{~d}$ course of intravenous Acyclovir. In the months immediately after, E. P. experienced severe loss of appetite and a 20-30 lb weight loss. By June, 1993 his clinical condition had stabilized; however, profound memory impairment has persisted to the present time.

Upon first meeting E. P., one is impressed by his healthy, well groomed appearance and his pleasant demeanor. E. P. stands 6 feet, $21 / 2$ inches tall and weighs $192 \mathrm{lbs}$. He walks with a slight limp caused by arthritis in his left knee. He is always agreeable and cooperative during testing sessions, and he particularly enjoys participating in computer-aided tests. During testing sessions, he will repeatedly marvel at the invention of the portable computer, often commenting that he "was born too early". His conversation is limited to events from his early life, e.g., his childhood on a farm, his teenage hobby as a ham radio operator, and his travels during World War II. Within a $1 \mathrm{hr}$ testing session, E. P. may recount the same story almost verbatim as many as 10 times.

Like patient H. M. (Corkin et al., 1997), E. P. is socially interactive but lacks initiative. On a typical day, E. P. has a light breakfast when he wakes up, and then he returns to bed where he listens to the radio. His wife reports that when he arises a second time, he will often return to the kitchen and have breakfast again, and sometimes he again returns to bed. He has had breakfast as many as three times in one morning before staying up for the day. E. P. chooses his own clothes and dresses himself. He needs no assistance in bathing or shaving, although he often needs reminders about these activities from his wife. In the morning, he alternates between taking short walks around his neighborhood and sitting in his backyard or in the living room. After lunch, he watches television or reads the newspaper or a magazine. Often, he will suggest that he and his wife go out, but once they leave the house (to go shopping, for example), he will become confused and ask to return home. He watches television after dinner, and retires early (7:00 P.M. or 8:00 P.M.). 


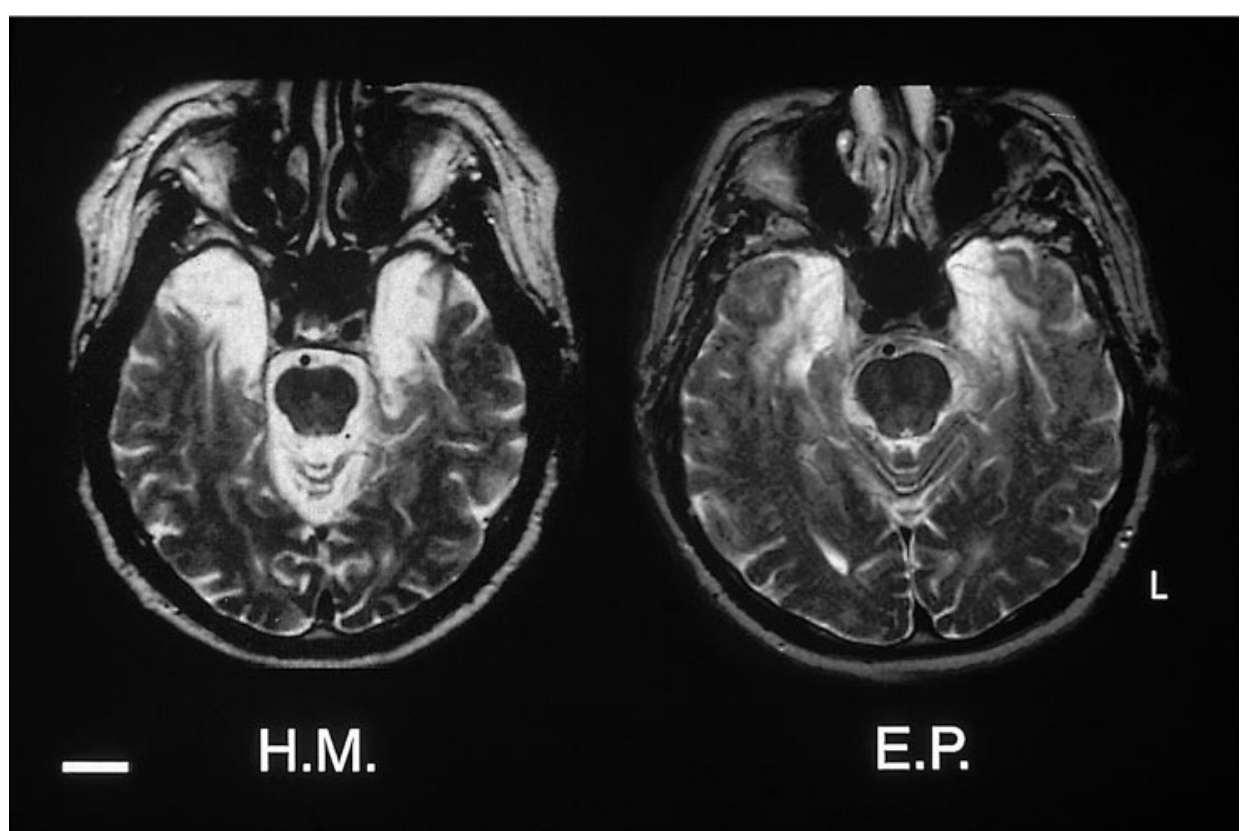

Figure 1. T2-weighted axial MRIs of patients E. P. (right) and H. M. (left), through the level of the temporal lobes. Damaged tissue is indicated by bright signal. Images are oriented according to radiological convention (the right side of the brain is on the left side of the image). Both patients sustained extensive damage to medial temporal lobe structures. Scale bar, $2 \mathrm{~cm}$ (applies to both panels). The MR image for H. M. is reprinted from Corkin et al. (1997), their Figure $4 D$.

\section{Medical history}

E. P. has a history of hypertension, arthritis (right elbow, left knee), hernia repair, and an uncomplicated myocardial infarction with complete recovery and without indication of cerebral ischemia. E. P. has no history of diabetes, heart or lung disease, headaches, seizures, stroke, or traumatic loss of consciousness. He currently takes medication for hypertension (Metoprolol; $50 \mathrm{mg} / \mathrm{d}$ ), for anxiety (Paroxetine; $20 \mathrm{mg} / \mathrm{d}$ ), and for high cholesterol (Atorvastatine; $10 \mathrm{mg} / \mathrm{d}$ ). E. P. stopped smoking in 1959. He does not currently drink alcohol, and his wife reports that he was never a heavy drinker.

\section{Neurological examination}

E. P.'s neurological status has remained stable since his diagnosis of encephalitis in 1992. On his most recent examination in 1995 he was found to be alert and attentive, but disoriented to place and time (month and year). His language output was fluent and nonparaphasic. He was able to copy nonsense figures and a cube, and showed no signs of spatial neglect. Examination of the cranial nerves revealed anosmia and mild difficulty hearing conversational speech. (This mild hearing loss is barely noticeable in conversation with E. P. and has never interfered with neuropsychological testing.) Examination of reflexes and posture, motor and somatosensory function, and coordination was unremarkable.

\section{Magnetic resonance imaging}

Patient E. P. We obtained MR images of EP's brain on two occasions, in 1994 and 1998, and summaries of these findings have appeared previously (Squire and Knowlton, 1995; Hamann and Squire, 1997; Reed and Squire, 1998; Buffalo et al., 1998; Schmolck et al., 2000a). MRIs were acquired in a 1.5 tesla GE Signa clinical scanner at the University of California San Diego Medical Center, using four different scanning protocols: (1) sagittal three-dimensional (3-D) MP-RAGE images, field of view (FOV) $=20 \mathrm{~cm}$, matrix $=256 \times 256(0.781 \mathrm{~mm}$ in-plane resolution $), 1.2$-mm-thick sections; (2) coronal oblique, T1-weighted images perpendicular to the long axis of the hippocampus (Press et al., 1989), FOV $=16$, matrix $=256 \times 256(0.625$ $\mathrm{mm}$ in-plane resolution), 5-mm-thick, interleaved sections; (3) coronal oblique, T2-weighted, proton density fast spin echo (FSE) images, perpendicular to the long axis of the hippocampus, $F O V=20$, matrix $=128 \times$ $256(1.56 \times 0.781 \mathrm{~mm}$ in-plane resolution $), 5$-mm-thick, interleaved sections; (4) axial T2-weighted, proton density FSE images, FOV $=20$ matrix $=256 \times 256(0.781 \mathrm{~mm}$ in-plane resolution $), 5$-mm-thick sections.

Control subjects. MR images of the brains of three right-handed, male control subjects (mean age, 78.6 years; mean education, 16 years) were acquired in a 1.5 tesla GE Signa clinical scanner at the Veterans Affairs Medical Center (San Diego, CA). A 3-D spoiled gradient-recalled acquisition in a steady state (SPGR) scanning protocol was used to collect images in the coronal (1.5-mm-thick sections) or the sagittal $(1.2-\mathrm{mm}$-thick sections) planes. For all images, the in-plane resolution was $1.0 \mathrm{~mm}$, and $\mathrm{FOV}=24 \mathrm{~cm}$

Data analysis. We first performed a qualitative analysis of the MR images of each participant using primarily T1-weighted sagittal, T1weighted coronal oblique, and T2-weighted axial images. We also imported the sagittal MP-RAGE images into the Analysis of Functional NeuroImages (AFNI) software program (Cox, 1996), so that the images could be reconstructed and analyzed in all three planes. Our qualitative analysis focused mainly on the temporal lobe, which was extensively damaged in E. P. A quantitative analysis was also accomplished by capturing AFNI images at $2 \mathrm{~mm}$ (subject $\mathrm{C} 2$ ) or $3 \mathrm{~mm}$ intervals (E. P., and controls $\mathrm{C} 1$ and C3) throughout the brain and importing them into the Canvas 5.0 software program. Images were reconstructed so that the voxel dimensions were the same across brains. We then calculated for each participant the volume of the frontal lobes, lateral temporal lobes, parietal lobes, occipital lobes, and insula in the following manner. First, we outlined each of these regions with the Canvas 5.0 polygon tool and calculated the total area by summing the areas for each hemisphere. The area of the ventricles was subtracted from relevant sections. We then multiplied the total area of each region by the image thickness.

The measuring technique described above was also used to calculate the volume of the lateral and third ventricles. We excluded the temporal horns of the lateral ventricles from these measurements, because they were substantially enlarged in E. P. (consistent with the tissue damage and atrophy in his medial temporal lobes). Excluding the temporal horns allowed for an estimate of cortical atrophy that was not influenced by E. P.'s medial temporal lobe abnormalities.

We measured the frontal lobe from the frontal pole to the caudal limit of the central sulcus. The ventral border of the frontal lobe is formed by the fundus of the superior limiting sulcus until the central sulcus appears more caudally. Measurement of the lateral temporal lobe included the inferior, middle, and superior temporal gyri, as they extend from the temporal pole to the splenium of the corpus callosum. On coronal sections, the outline for the lateral temporal lobe thus extended from the fundus of the lateral occipitotemporal sulcus (medially) to the fundus of the inferior limiting sulcus (laterally). The parietal lobe measurement extended rostrally to the central sulcus. Caudally, it extended beyond the caudal extent of the lateral sulcus to meet with the temporal and occipital lobes. The occipital lobe measurement extended to the parietal lobe at the level of the parietooccipital fissure and to the temporal lobe at approximately the level of the splenium of the corpus callosum where the calcarine sulcus merges with the parieto-occipital fissure.

In the case of the insula, the presence of white matter damage deep to the insula (see Results) made it difficult to determine the gray-white matter border of this region, and therefore difficult to make a satisfactory volume estimate. We calculated total insula area by measuring the perimeter of the insula from the superior limiting sulcus to the inferior limiting sulcus in $2-3 \mathrm{~mm}$ intervals, and then multiplied the sum perimeter by the image thickness.

\section{Neuropsychology}

E. P. was assessed on a number of tests of anterograde and retrograde memory, as well as on other tests of cognitive function. For many of the tests, E. P.'s performance was compared to the performance of four healthy, age- and education-matched men who were volunteers or employees at the San Diego Veterans Affairs Medical Center. As a group they averaged 75.3 years of age and had 12.8 years of education. For other tests, E. P.'s performance was compared to previously published scores of normal subjects. 


\section{RESULTS}

\section{Magnetic resonance imaging}

\section{Terminology}

The description of E. P.'s medial temporal lobe follows the nomenclature used by Amaral and Insausti (1990) and Corkin et al. (1997). The hippocampal formation comprises the dentate gyrus, hippocampus, subicular complex (parasubiculum, presubiculum, and subiculum proper), and entorhinal cortex. Rostrally, the intraventricular portion of the hippocampal formation (dentate gyrus, hippocampus, and subiculum) begins $\sim 3.5 \mathrm{~cm}$ from the temporal pole and continues for $\sim 4.0 \mathrm{~cm}$ caudally, to a point $\sim 7.5 \mathrm{~cm}$ from the temporal pole. The entorhinal cortex begins $\sim 2.5 \mathrm{~cm}$ from the temporal pole, on the parahippocampal gyrus, and continues for $\sim 2.5 \mathrm{~cm}$ caudally to the anterior limit of the lateral geniculate nucleus. The entorhinal cortex is bounded medially by the subicular complex and laterally by the perirhinal cortex. The perirhinal cortex extends from the temporal pole and continues ventrocaudally, for $\sim 5 \mathrm{~cm}$, ending at the posterior border of the medially situated entorhinal cortex; that is, at about the anterior limit of the lateral geniculate nucleus. The perirhinal cortex lies on both banks of the collateral sulcus for most of its rostrocaudal extent (the collateral sulcus is located between the medially situated parahippocampal gyrus and the laterally situated fusiform gyrus). The perirhinal cortex is bordered caudally by the parahippocampal cortex, which comprises the caudal portion of the parahippocampal gyrus and extends to the caudal extent of the temporal lobe (i.e., to the level of the splenium of the corpus callosum). The amygdala is located $\sim 3 \mathrm{~cm}$ caudal to the temporal pole and is immediately dorsal to the entorhinal and perirhinal cortices.

\section{General appearance of the brain}

The most striking feature of E. P.'s brain is severe, bilateral medial temporal lobe pathology (Figs. 2-4). The damage is most severe in the anterior temporal lobe, and includes the amygdala, hippocampus, entorhinal, and perirhinal cortices, bilaterally (Figs. 2E-J, $5 A-C)$. There is also involvement of the rostral fusiform gyrus and the rostral parahippocampal cortex, bilaterally (Fig. $5 B-E$ ). Beyond the caudal limit of the fusiform and parahippocampal damage (5.1 $\mathrm{cm}$ from the temporal pole on the left side, and $6.3 \mathrm{~cm}$ from the pole on the right side), the hippocampal lesion continues bilaterally to a point $7 \mathrm{~cm}$ from the tip of the temporal poles and includes the full rostrocaudal extent of the hippocampus (Fig. 4B,C).

There is some white matter damage in E. P.'s brain, visible as significant hyperintensity on T2-weighted images. The abnormalities are apparent in the external capsule, in the white matter deep to the insula, the corona radiata, and in periventricular regions. It is not clear whether this fiber damage is directly related to the encephalitis or whether it represents premorbid leukoencephalopathy (white matter disease), or both. In the temporal lobe, the subcortical lesions invade portions of the laterally adjacent white matter, at the level of the amygdala and the rostral hippocampus. This damage may likely encroach on a portion of an area referred to as the temporal stem, a somewhat vaguely defined fiber bundle that contains afferent and efferent connections of the temporal cortex and amygdala.

There is also notable volume loss in some regions of E. P.'s brain, as indicated by the presence of prominent sulci. In particular, the Sylvian fissures are enlarged in the anterior region of the temporal lobes (Fig. 5A-E). The atrophy is more prominent in the cerebral hemispheres than in the brainstem or cerebellum. Additionally, the temporal lobes appear disproportionately shrunken when compared to other cortical regions, and this volume loss appears to be associated with the focal brain damage in the temporal lobes. The volume of E. P.'s frontal lobes, occipital lobes, right parietal lobe, and ventricles are comparable in volume to the control brains, whereas his insula, lateral temporal lobes, and left parietal lobe are reduced in volume (Table 1).

There are no other gross abnormalities in E. P.'s brain, with the exception of a small area of abnormal signal intensity in the vicinity of the caudal medulla, which is unlikely to be related to his encephalitis.

\section{Temporal lobe findings}

Starting at the temporal poles, there is extensive bilateral damage to the medial temporal lobe, which at this level includes the polar portion of the perirhinal cortex. The abnormal tissue appears dark on the T1-weighted images (Figs. 2, 5). Lateral aspects of the cortex, including the inferior, middle, and superior temporal gyri, are intact. The damage continues caudally to include all of the amygdala, all of the entorhinal cortex, and all of the perirhinal cortex, bilaterally. At the level of the amygdala, the cortical damage extends lateral to the parahippocampal gyrus to include the fusiform gyrus, bilaterally. This pattern remains constant through the caudal amygdala and rostral hippocampus (4-5 cm from the temporal pole), where the damage on the left becomes more localized to the medially situated parahippocampal cortex. Here, the left collateral sulcus is visible for the first time, and the signal within the left fusiform gyrus becomes less abnormal. The left parahippocampal cortex continues to be severely atrophic (with hypointense signal) for $\sim 1.0 \mathrm{~cm}$ further caudally, at which point it develops a more normal appearance. On the right side, the cortical damage extends further caudally than on the left. Damage to the right fusiform gyrus continues to $\sim 5.0 \mathrm{~cm}$ from the temporal pole. Additionally, damage to the right parahippocampal cortex continues for $\sim 1.0 \mathrm{~cm}$ beyond the caudal limit of the right fusiform damage.

The temporal horns of the lateral ventricles are grossly enlarged at the most rostral aspect of the hippocampus (Fig. $5 \mathrm{C}$ ). Within the ventricles, nothing remains of the hippocampus except a small tag of vestigial tissue on each side (Fig. $5 C-E$ ). The total volume of this tissue remnant is $\sim 10 \%$ of the average volume of the hippocampus of the three control brains that were analyzed ( 0.28 vs $\left.2.64 \mathrm{~cm}^{3}\right)$. The abnormal appearance of this tissue and the absence of the entorhinal cortex (which originates the major cortical afferents of the hippocampus) make it quite unlikely that the remnant tissue is functional.

We also quantified the amount of intact cortical tissue in the parahippocampal cortex and the fusiform gyrus, which sustained incomplete damage. These results are described below.

Summary for parahippocampal cortex. There is bilateral damage to the anterior portion of the parahippocampal cortex, which is more extensive on the right side than on the left (Fig. $5 E$ ). On the left, the damage includes the rostral $5 \mathrm{~mm}$ of the parahippocampal cortex $(18 \%)$, and on the right the damage includes the rostral 1.6 $\mathrm{cm}(57 \%)$ of the parahippocampal cortex.

Summary for fusiform gyrus. There is bilateral damage to the anterior portion of the fusiform gyrus, which is more extensive on the right side than on the left side (Fig. $5 A-D$ ). On the left, the damage includes the rostral $4 \mathrm{~cm}$ of the fusiform gyrus $(40 \%$ damage). On the right, the damage includes the rostral $5 \mathrm{~cm}$ of the fusiform gyrus (53\% damage).

\section{Cortical atrophy (Table 1)}

Inferior, middle, and superior temporal gyri. E. P.'s lateral temporal lobes (inferior, middle, and superior temporal gyri) are smaller than the lateral temporal lobes of the three control brains. The average volume for E. P.'s right and left lateral temporal lobes (52 $\mathrm{cm}^{3}$ ) falls outside the $95 \%$ confidence interval of the control volume (mean volume, $64 \mathrm{~cm}^{3}$; range, 61-66).

Frontal lobes. E. P.'s frontal lobe volume is comparable to the frontal lobe volume of the three controls. The average volume for E. P.'s right and left frontal lobes $\left(156 \mathrm{~cm}^{3}\right)$ is well within the range of control values (mean volume, $153 \mathrm{~cm}^{3}$; range, $145-167 \mathrm{~cm}^{3}$ ).

Parietal lobes. E. P.'s parietal lobe volume is smaller than the parietal lobe volume of the control brains. The average volume for E. P.'s right and left parietal lobes $\left(144 \mathrm{~cm}^{3}\right)$ falls outside the $95 \%$ confidence interval of the control volume (mean volume, $180 \mathrm{~cm}^{3}$, range $169-190 \mathrm{~cm}^{3}$ ). However, E. P.'s right parietal lobe volume is within the control range. 

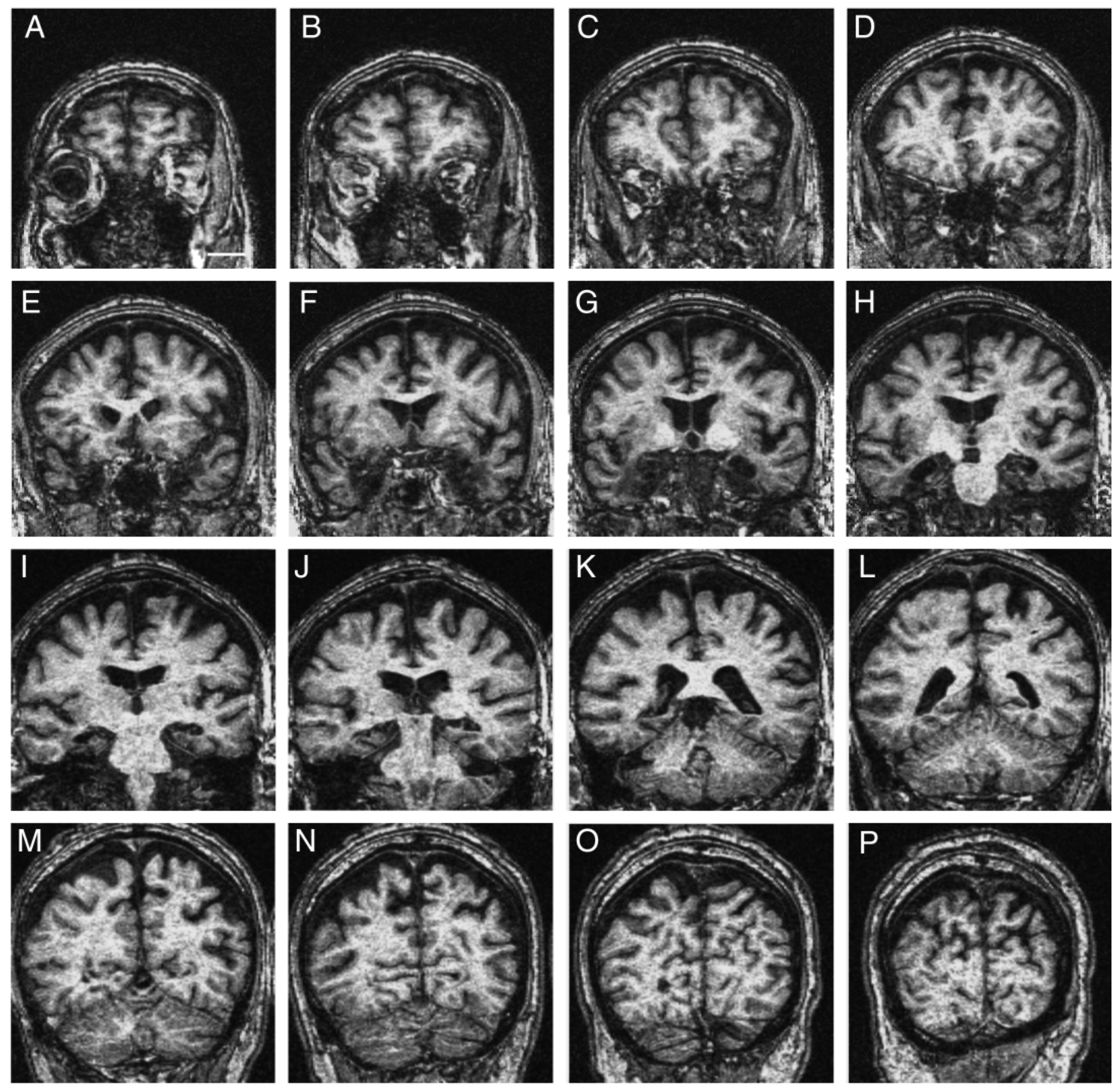

Figure 2. T1-weighted coronal images arranged from rostral $(A)$ to caudal $(P)$ through E. P.'s brain. Images are 0.781-mm-thick and are spaced 8.6 mm apart. Damaged tissue is indicated by dark signal. Images are oriented as in Figure 1. E. P.'s temporal lobe damage can be seen in $D-K$. Scale bar: $A$, 2 $\mathrm{cm}$ (applies to all panels).

Table 1. Brain tissue measurements

\begin{tabular}{|c|c|c|c|c|c|c|c|c|c|c|c|c|c|c|c|c|c|c|}
\hline & \multicolumn{3}{|c|}{ Frontal lobes $\left(\mathrm{cm}^{3}\right)$} & \multicolumn{3}{|c|}{$\begin{array}{l}\text { Lateral temporal } \\
\text { lobes }\left(\mathrm{cm}^{3}\right)\end{array}$} & \multicolumn{3}{|c|}{$\begin{array}{l}\text { Hippocampus } \\
\left(\mathrm{cm}^{3}\right)\end{array}$} & \multicolumn{3}{|c|}{$\begin{array}{l}\text { Occipital lobes } \\
\left(\mathrm{cm}^{3}\right)\end{array}$} & \multicolumn{3}{|c|}{ Insula $\left(\mathrm{cm}^{2}\right)$} & \multicolumn{3}{|c|}{ Parietal lobes $\left(\mathrm{cm}^{3}\right)$} \\
\hline & Right & Left & Avg & Right & Left & Avg & Right & Left & Avg & Right & Left & Avg & Right & Left & Avg & Right & Left & Avg \\
\hline Patient E.P. & 139 & 173 & 156 & 47 & 57 & 52 & 0.26 & 0.29 & 0.28 & 90 & 71 & 81 & 14 & 13 & 14 & 155 & 133 & 144 \\
\hline Control 1 & 151 & 183 & 167 & 58 & 63 & 61 & 2.60 & 2.78 & 2.69 & 92 & 83 & 88 & 16 & 16 & 16 & 191 & 170 & 181 \\
\hline Control 2 & 142 & 149 & 146 & 66 & 65 & 66 & 2.99 & 2.84 & 2.91 & 87 & 85 & 86 & 16 & 15 & 16 & 194 & 186 & 190 \\
\hline Control 3 & 146 & 143 & 145 & 64 & 63 & 64 & 2.58 & 2.03 & 2.31 & 58 & 55 & 57 & 15 & 17 & 16 & 155 & 182 & 169 \\
\hline Control average & 146 & 158 & 153 & 63 & 64 & 64 & 2.72 & 2.55 & 2.64 & 79 & 74 & 77 & 16 & 16 & 16 & 180 & 179 & 180 \\
\hline SD & 4.5 & 21.6 & 12.4 & 4.2 & 1.2 & 2.5 & 0.2 & 0.4 & 0.3 & 18.4 & 16.8 & 17.3 & 0.4 & 0.8 & 0.2 & 21.7 & 8.3 & 10.5 \\
\hline
\end{tabular}




\begin{tabular}{lll}
\hline Table 2. Anterograde memory test performance & \\
& E. P. & Control means $(n=8)$ \\
\hline $\begin{array}{l}\text { Two-choice recognition } \\
\quad \text { memory }\end{array}$ & \\
$\quad$ Words (50) & 24 & 48.4 \\
$\quad$ Faces (50) & 28 & 41.9 \\
Complex design & & \\
$\quad$ Copy (36) & 27 & 30.3 \\
$\quad$ Recall (36) & 0 & 20.6 \\
Paired-associate learning & & \\
$\quad$ Trial 1 (10) & 0 & 6.0 \\
$\quad$ Trial 2 (10) & 0 & 7.6 \\
$\quad$ Trial 3 (10) & 0 & 8.9 \\
Prose recall & & \\
No delay (21) & 3 & 7.6 \\
Delay (21) & 0 & 6.4
\end{tabular}

The mean scores for control subjects for these tests are from Squire and Shimamura (1986). The two-choice recognition memory scores are based on a $24 \mathrm{hr}$ recognition test of 50 words or 50 faces (modified from Warrington, 1984; maximum score, 50; chance, 25). The complex design test score is based on the copy and delayed (12 $\mathrm{min})$ reproduction of the Rey-Osterrieth figure (Osterrieth, 1944; maximum score, 36; see also Figure 6). The paired-associates scores are the number of word pairs recalled on three successive trials (maximum score, 10/trial). The Prose recall scores are based on the number of segments recalled from a short prose passage that was read to the subjects. Recall was tested immediately and after $12 \mathrm{~min}$. Note that the no-delay tes requires recall of more information than can be retained in immediate memory, and amnesic patients often obtain impaired scores on this test.

Occipital lobes. E. P.'s occipital lobe volume is also comparable to the occipital lobe volume of the three controls. The average volume for E. P.'s right and left occipital lobes $\left(81 \mathrm{~cm}^{3}\right)$ is well within the range of control values (mean volume, $77 \mathrm{~cm}^{3}$; range, $\left.57.0-88 \mathrm{~cm}^{3}\right)$.

Insula. E. P.'s insula is smaller bilaterally than the insula of the control subjects. The average area for E. P.'s right and left insula $\left(13.8 \mathrm{~cm}^{2}\right)$ is outside the $95 \%$ confidence interval of the control area (mean area, $15.8 \mathrm{~cm}^{2}$; range $=15.6-16.0 \mathrm{~cm}^{2}$ ).

Ventricles. As noted above, the temporal horns of E. P.'s lateral ventricles are grossly enlarged. The remaining portions of E. P.'s lateral ventricles and his third ventricle have a total volume of 26.3 $\mathrm{cm}^{3}$, which falls within the $95 \%$ confidence interval of the control volume (mean volume, $47 \mathrm{~cm}^{3}$; range, $33-71 \mathrm{~cm}^{3}$ ).

\section{Neuropsychological findings}

\section{Intellectual function}

In 1994, E. P. obtained a full-scale IQ score of 103 on a standard test of intellectual function [Weschler Adult Intelligence ScaleRevised (WAIS-R)]. His performance was low on two subtests (WAIS-R: information, 17; vocabulary, 33; E. P.'s four controls averaged 23 and 56, respectively), consistent with his mild impairment on tests of semantic knowledge (see below). E. P.'s performance on standard tests of intellectual function has remained stable during the 6 years that he has been tested in our laboratory. E. P.'s premorbid reading ability, measured by the Wide Range Achievement test (WRAT 3), was estimated to be at the 12th grade level, consistent with his education. Finally, E. P. obtained a total score of $118(81.9 \%)$ on the Dementia Rating Scale (DRS; Mattis, 1976), with most points lost on the memory subportion of the test (15 points lost). Eleven normal controls (mean age, 60.8 years) averaged 139.7 (97\%) on this same test (Janowsky et al., 1989).

\section{Immediate memory}

Like other amnesic patients (Baddeley and Warrington, 1970; Cave and Squire, 1992), E. P.'s immediate memory is intact as measured by digit span. The digit span test, which was given to E. P. on 12 occasions, was taken from the forward digit span subtests of the WAIS-R (given nine times), the Wechsler Memory Scale-Revised (WMS-R) (given twice), and the WAIS-III (given once). E. P.'s average forward digit span was 6.6 (range, 5-8), which was within the range of scores obtained by the four healthy control subjects (mean digit span of controls, 7.3; range, 4-9). In addition, E. P.'s digit span performance was comparable to the performance of six amnesic patients with confirmed or suspected damage to the hippocampal formation (mean digit span, 6.8; Cave and Squire, 1992), and comparable to the performance of the densely amnesic patient H. M., who obtained a digit span of 6.0 on the WMS-R (Keane et al., 1995).

The Spatial Span task from the WMS-III provides a nonverbal measure of immediate memory. The experimenter points to a series of blocks on a three-dimensional board, and the participant must then point to the same blocks in the same order. E. P. and his four controls were given the spatial span task on four different occasions. E. P. had an average spatial span of 5.5 blocks (range, 4-6), and the controls had an average spatial span of 5.9 blocks (range, 4-7).

\section{Declarative memory}

Despite E. P.'s intact performance on tests of immediate memory, his declarative memory is profoundly impaired, as documented by every test of delayed recall and recognition that he has ever been given (Squire and Knowlton, 1995; Hamann et al., 1997; Hamann and Squire, 1997; Reed et al., 1997; Reber and Squire, 1998; Buffalo et al., 1998; Teng and Squire, 1999; Stark and Squire, 2000). E. P. obtained scores of 94, 57, 82, 61, and 56 on the five indices of the WMS-R (attention-concentration, verbal memory, nonverbal memory, general memory, and delayed memory). These five indices yield means of 100 in the normal population (SD, 15). Table 2 and Figure 6 show a sample of E. P.'s performance on other memory tests. He exhibited no capacity for declarative memory on any of the tests. E. P.'s severe memory impairment is particularly well illustrated by his poor performance on tests of recognition memory (Fig. 7). In two different studies (Hamann and Squire, 1997; Stark and Squire, 2000), E. P. saw 20 or 24 words and after a 5 or 10 min delay was given a test of either yes-no recognition or forced-choice recognition. A total of 42 such tests were given, and his average score across all tests was $49.3 \%$ correct. That is, he performed at chance levels.

E. P. moved to his present home in 1993, after he became amnesic. A final example of E. P.'s anterograde memory impairment is his inability to describe how he would travel from his home to locations in his neighborhood that he visits with his wife (e.g., the supermarket, the post office; Teng and Squire, 1999). Moreover, in 1999, he was unable to draw a floor plan of his present home. Finally, although he lives $<2$ miles from the Pacific Ocean, he cannot when asked point in the direction of the ocean.

Unlike other amnesic patients, including patient H. M. (Freed et al., 1987), E. P.'s recognition memory performance did not benefit by extended exposure to study items (Reed et al., 1997). On three separate occasions, E. P. viewed 40 pictures for either $0.2 \mathrm{sec}$ each (short exposure) or $20 \mathrm{sec}$ each (extended exposure), and $10 \mathrm{~min}$ later took a yes-no recognition memory test. He was not able to recognize the pictures after seeing them in the extended exposure condition, and he obtained an average score of $50.6 \%$ correct across the three tests. In contrast to E. P., H. M. benefited from extended study time (H. M.'s average score across four tests, 78.8\%; Freed et al., 1987). The procedures for the tests given to E. P. and H. M. were the same, with the exception that E. P. was presented with a shorter list of pictures (EP, 40; H. M., 120). E. P.'s recognition memory performance was similarly poor when he was tested in a two-alternative, forced-choice format, and when the tests involved shorter lists of to-be-remembered items, increased study time, or increased numbers of exposures to each item.

\section{Retrograde memory}

Patient E. P. has severe and extensive retrograde amnesia for facts and events but is capable of retrieving memories from his early life. For example, he is extremely impaired on tests of recall and recognition for public events, famous faces, and famous names that 

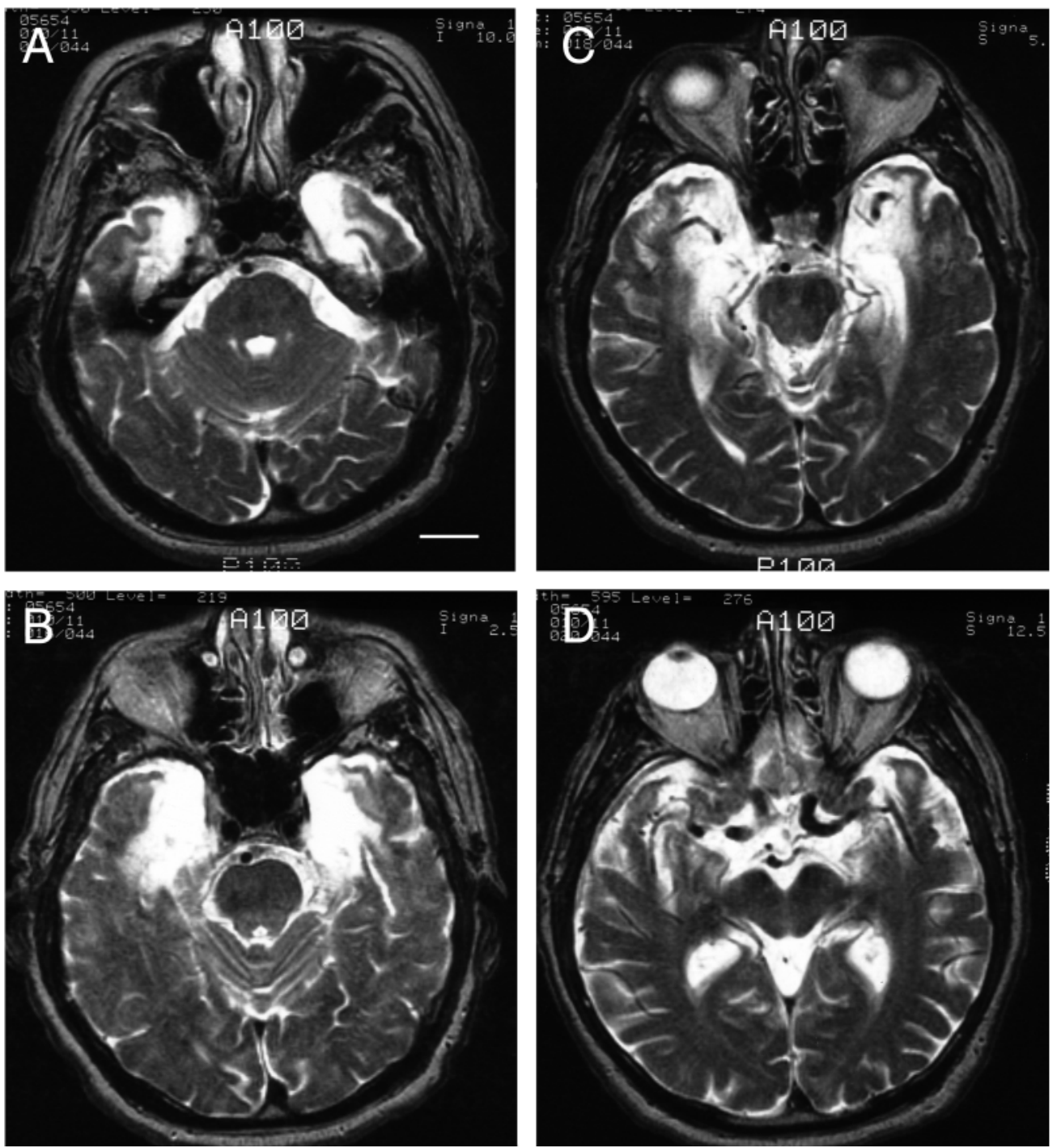

Figure 3. T2-weighted axial images, arranged from ventral $(A)$ to dorsal $(D)$, indicating the extent of damage in E. P.'s anterior temporal lobes (bright signal areas). Images are 5-mm-thick and are spaced $7.5 \mathrm{~mm}$ apart. Images are oriented as in Figure 1 . Scale bar: $A, 2 \mathrm{~cm}$ (applies to all panels).
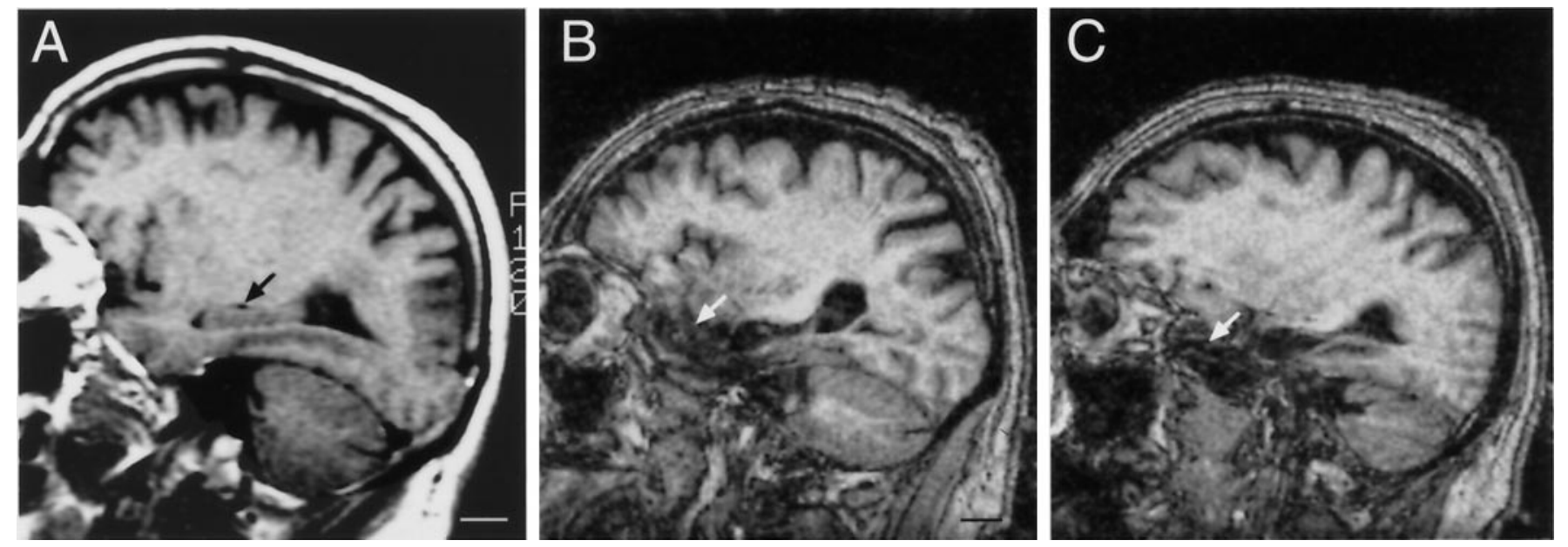

Figure 4. A shows a T1-weighted parasagittal image from the left hemisphere of a 74-year-old control subject. $B$ and $C$ show parasagittal images through the left and right hemispheres, respectively, of E. P.'s brain. Compare the intraventricular portion of the hippocampal formation of the control subject $(A$, black arrow), with the absence of hippocampal tissue in E. P.'s ventricles $(B, C)$. The damaged portion of E. P.'s anterior temporal lobes is indicated with white arrows in $B$ and $C$. Scale bars: $A, 2 \mathrm{~cm} ; B, 2 \mathrm{~cm}$ (also applies to $C$ ). 

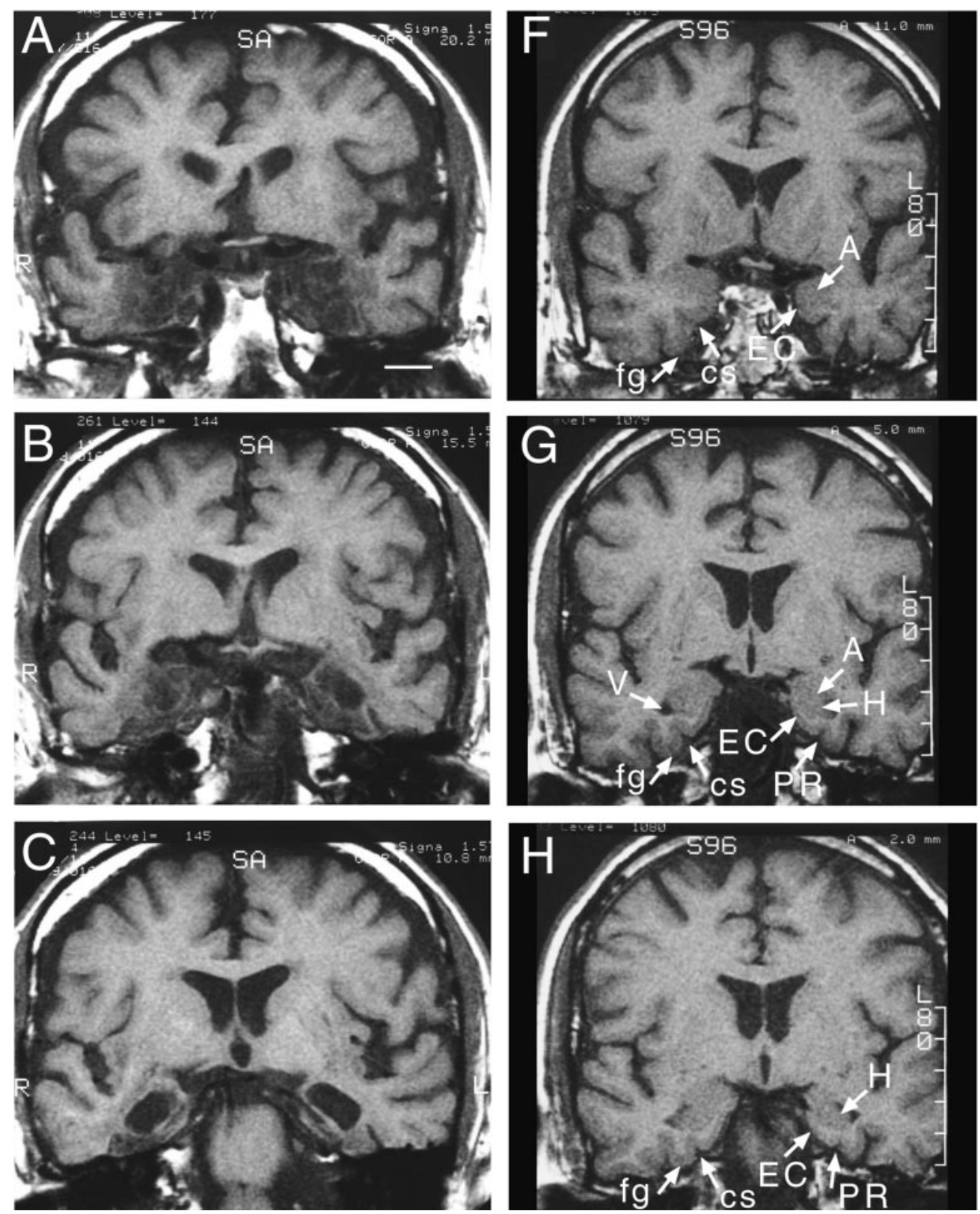

Figure 5. Five T1-weighted coronal images through the temporal lobes of E. P. are presented from rostral $(A)$ to caudal $(E)$. Coronal images from the same 74-year-old control shown in Figure 4 are presented in panels $F-J$. Damaged tissue in E. P. is indicated by dark signal. Images for E. P. were selected at 4-6 mm intervals, and images from the control brain were selected to match as closely as possible the levels illustrated for E. P. Images are oriented as in Figure 1. Scale bar: $A, 2 \mathrm{~cm}$ (applies to all panels). In $A$ and $B$, the amygdala, rostral hippocampus, parahippocampal gyrus (comprising the entorhinal and perirhinal cortices at this level), and the fusiform gyrus are extensively damaged bilaterally. In $C$, the temporal horns of the lateral ventricles are grossly dilated, and nothing remains of the intraventricular portion of the hippocampal formation except perhaps a thin remnant of tissue bilaterally. The damage to the fusiform gyrus can be seen on both sides, although the damage appears less severe on the left. The entorhinal and perirhinal cortices are severely compromised bilaterally. In $D$, the temporal horns remain enlarged bilaterally, and only a tag of tissue is present within the ventricles. The appearance of the fusiform gyrus is improved on the left side, although the medially adjacent parahippocampal gyrus is damaged and severely atrophic bilaterally. In $E$, the hippocampus continues to be severely compromised bilaterally. The right temporal cortex is more atrophic than the left, although an abnormal (dark) signal is present in the parahippocampal gyrus (comprising the parahippocampal cortex at this level) on the left. The left fusiform gyrus appears to be intact. $A$, Amygdala; $c s$, collateral sulcus; $E C$, entorhinal cortex; $f g$, fusiform gyrus; $H$, hippocampus; $P R$, perirhinal cortex; $P H$, parahippocampal cortex; $V$, ventricle. Figure continues.

came into the news after 1950. His performance is somewhat better, however, when the tests involve subject matter that came into the news before 1950 (Reed and Squire, 1998).

E. P.'s performance on the Autobiographical Memory Interview (AMI) (Kopelman et al., 1989) provides a particularly striking illustration of his retrograde amnesia (Fig. 8). The AMI is a structured interview that asks for detailed information about three periods of life (i.e., childhood, early adult life, and recent life). Within each of these periods E. P.'s memory was tested for both personal semantic knowledge (e.g., What was your home address while attending high school?) and autobiographical memory (e.g.,
Describe an incident that occurred while you were attending elementary school). The accuracy of all his responses was corroborated by at least two family members.

For the recent time period, E. P. performed extremely poorly. He did better at answering questions about his early adult life, but his scores were still below (personal semantic memory) or at the low end of the range (autobiographical memory) of the control scores. In contrast, E. P. performed normally when answering questions about his childhood, scoring nearly as high as the highestscoring control subjects.

Another striking example of E. P.'s capacity to recall memories 

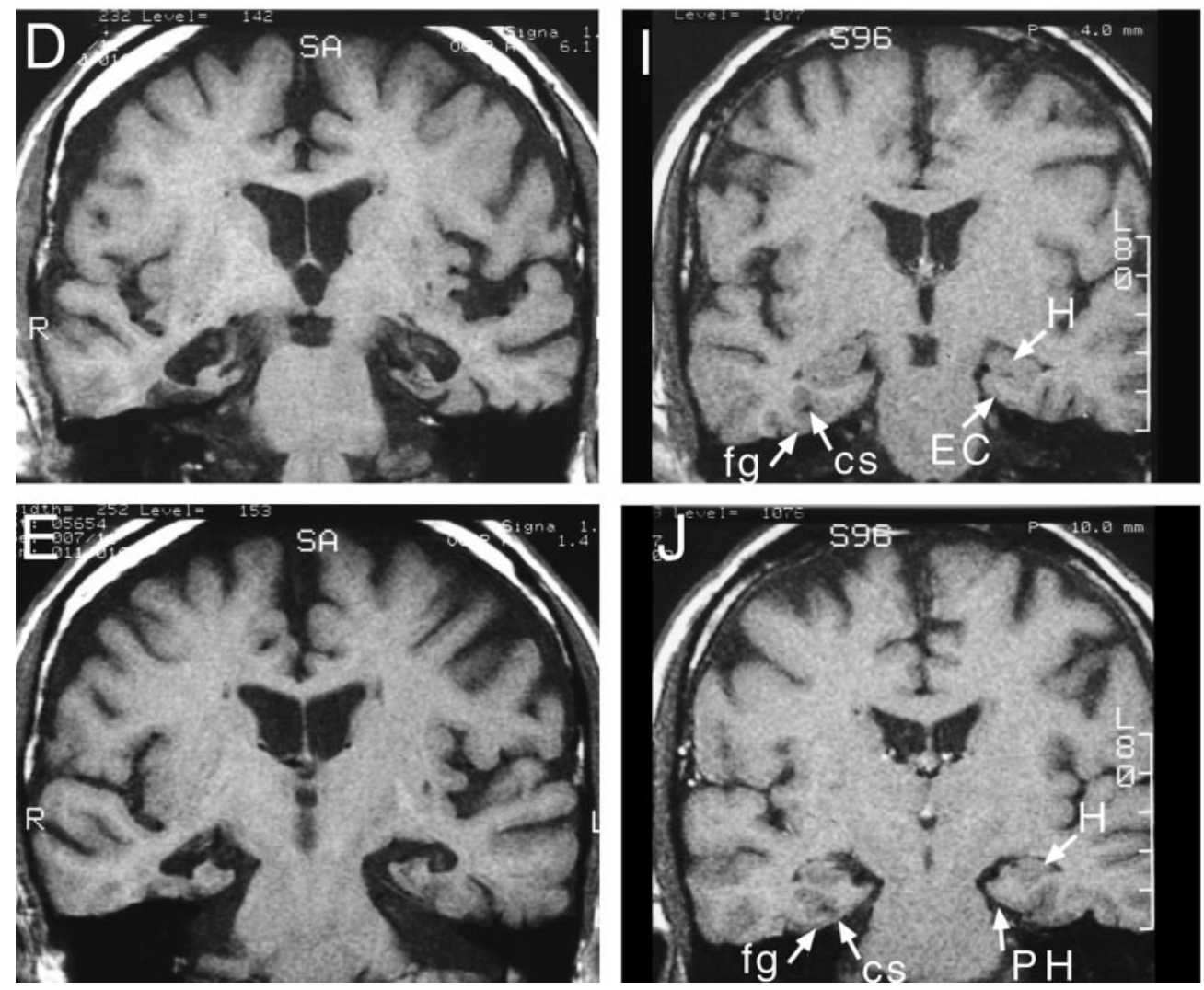

Figure 5 continued.

from his early life comes from tests of his spatial knowledge about the town in which he grew up (Fig. 9; Teng and Squire, 1999). E. P. was asked to describe how he would navigate from his home to different locations in the area (familiar navigation), between different locations in the area (novel navigation), and between these same locations if a main street were blocked off (alternative routes). He was also asked to imagine himself in a particular orientation at certain locations and then to point toward specific landmarks (pointing to landmarks). On all tests, his performance was comparable to the performance of five individuals who attended E. P.'s high school at the same time as he did, lived in the region for about as long as he did, and, like E. P., moved away from the area as young adults.

\section{Nondeclarative memory}

Patient E. P.'s nondeclarative memory is intact as measured by several tests, including perceptual priming (word-stem completion and perceptual identification; Hamann and Squire, 1997, Stark and Squire, 2000), learning of a visuomotor skill (Reber and Squire, 1998), and learning of category prototypes (Squire and Knowlton, 1995). In word-stem completion priming (Hamann and Squire, 1997; Fig. 10a), E. P. first saw 24 words. Then, after a 5 min delay, he saw 48 three-letter word stems (e.g., MOT) and was asked to complete each stem to form the first English word that came to mind. Twenty-four stems corresponded to study list words, and the remaining 24 stems corresponded to words that had not been studied (baseline items). On six separate tests, E. P. tended to complete word stems with words he had read earlier and exhibited this effect to the same extent as controls. Similarly, he performed like controls on 12 separate tests of perceptual identification priming (Fig. 10b). Specifically, when asked to identify 48 briefly flashed words, he identified successfully the words that he had read earlier much more frequently than newly presented words.

E. P. also learned a visuomotor skill (the serial reaction task) at the same rate as controls (Reber and Squire, 1998). In this task, a cue (an asterisk) was presented on a computer screen in any of four possible locations. A response key was located directly below each cue location. E. P. was asked to respond to the cue as rapidly as possible by pressing the key beneath the cue. A correct keypress caused the cue to disappear and then reappear in a new location after a $250 \mathrm{msec}$ delay. The task was administered in 60-trial blocks, and each block contained five repetitions of a 12-location sequence. Across a 20-block session (1200 trials), E. P.'s reaction time for making keypresses gradually decreased at the same rate as control subjects.

We have also noted at least two ways in which E. P.'s behavior has changed during the time that we have known him, both of which may be attributable to his capacity for nondeclarative memory. The first example concerns his reactions to his testers. During the first 2 or 3 years in which we visited his house, he was wary and slow to accept the idea that we wished to talk to him and administer tests. After some conversation, and with encouragement from his wife, E. P. would after a number of minutes seat himself at a table for testing. During the subsequent years, the same tester has visited his house more than 150 times. Now, when she arrives he greets her in a friendly manner and moves readily and promptly to the testing table even when his wife is not present. Yet, his pattern of greeting and acceptance occurs without any recognition of who the tester is, and he will repeatedly deny that he has seen her before.

The second example concerns E. P.'s reactions to the test materials. One particular test, which E. P. has worked on more than 90 times over the course of several years, requires him to use the eraser-end of a pencil to touch a computer screen. After approximately 50 repetitions of this test procedure, E. P. began regularly to pick up the pencil and orient the eraser-end toward the computer screen before he was told even that he was to use a pencil in the test. Yet, E. P. always denies that he has taken the test before and disclaims any sense of familiarity toward it.

We take these examples of behavioral change to be instances of habit learning, which E. P. has acquired gradually and which has 

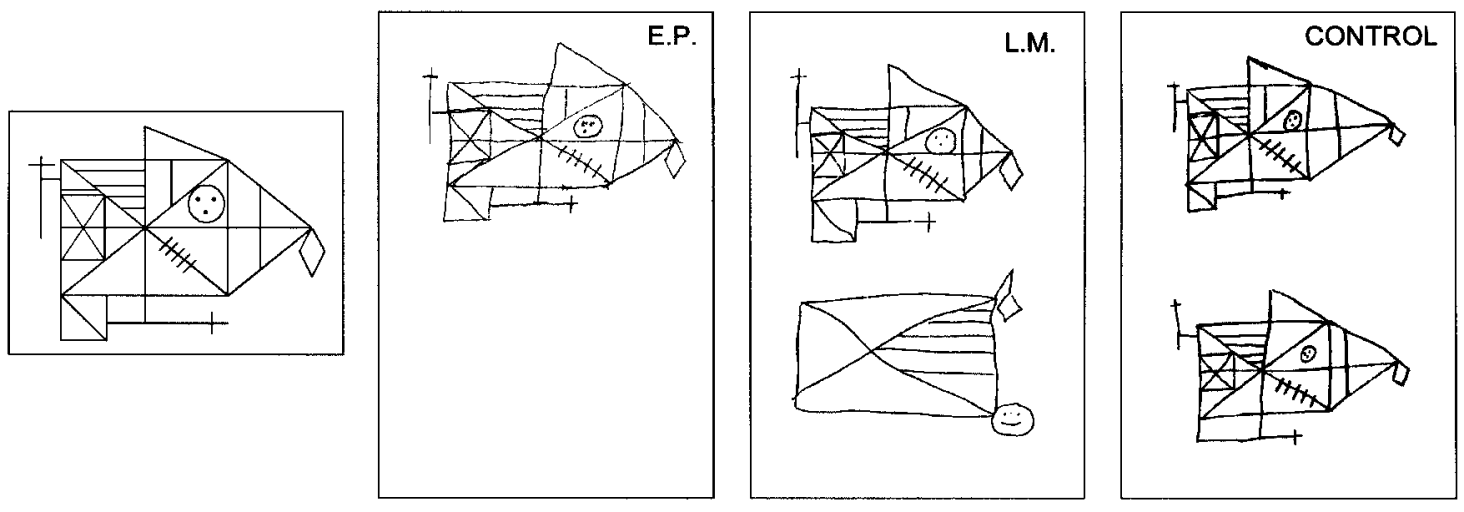

Figure 6. The Rey-Osterrieth figure. Subjects are asked to copy the figure illustrated in the small box in the left panel and, 10-15 min later, to reproduce it from memory. The copy (top) and reproduction (bottom) for E. P., for amnesic patient L. M. (Rempel-Clower et al., 1996) and for a representative control are shown in the larger panels at right. E. P. did not recall copying the figure. Encouraged to draw whatever came to mind, he declined to try.

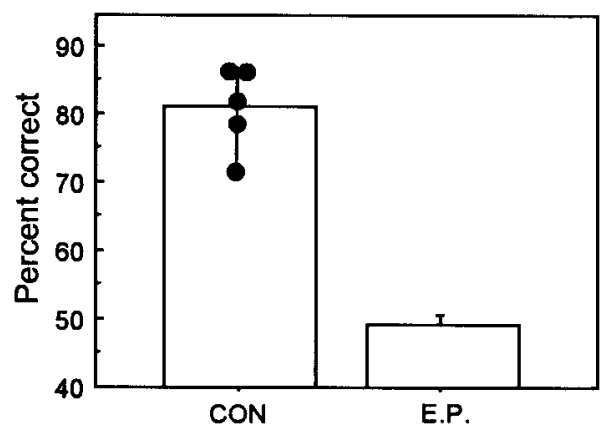

Figure 7. E. P.'s average performance on 42 different tests of recognition memory for words (Hamann and Squire, 1997, 12 tests; Stark and Squire, 2000,30 tests). Half of the tests were two-alternative forced choice, and half were yes-no recognition. The same five healthy control subjects took all 42 tests. Brackets for E. P. indicate the SEM. The data points for the control group $(C O N)$ indicate each participant's mean score across all 42 recognition memory tests. E. P.'s average performance $(49.3 \%$ correct) was $>5$ SDs below the average performance of control subjects $(81.1 \%$ correct; SD, 6.3$)$ and not different from chance.

allowed him to modify his behavior in response to regularities in his environment.

\section{Frontal lobe function}

Dementia rating scale (DRS). The initiation and perseveration subscale of the DRS is sensitive to frontal lobe damage (Janowsky et al., 1989). E. P.'s score on this subscale was comparable to the score of control subjects [E. P.'s score, 36 (97.3\%); control score, 36.5 (98.7\%), range, 33-37]. He performed better than amnesic patients with alcoholic Korsakoff's syndrome, who have both diencephalic lesions and frontal lobe atrophy (mean, 88\%; range, 78-97\%) and better than patients with left or bilateral frontal lobe lesions (mean, $78 \%$; range, 70-86\%; Janowsky et al., 1989).

WMS-R. Like other amnesic patients (Janowsky et al., 1989), E. P. scored well on the attention-concentration index (E. P., 94; 12 other amnesic patients, 96.8) and low on the delayed memory index (E. P., 56; other amnesic patients, 56). In contrast, patients with frontal lobe lesions scored low on the attention-concentration index and better on the delayed memory index (attention-concentration, 83.3 vs delayed memory, 94.5; $n=7$; Janowsky et al., 1989).

Wisconsin card-sorting task. E. P. was given the Wisconsin Card Sorting Test (WCST) in 1994 and again in 1998. On both occasions he was unable to sort any categories, and he committed 50.8 and $73.4 \%$ perseverative errors, respectively. Although this test is often considered to be diagnostic of frontal lobe dysfunction, Anderson et al. (1991) found no consistent relationship between poor WCST performance and structural damage to the frontal lobes in 91 patients with focal brain lesions resulting from cerebrovascular accident $(n=71)$ or from neurosurgical resection for treatment of a tumor or seizures $(n=20)$. Likewise, Teuber et al. (1951) found no differences in card-sorting ability among 131 World War II veterans with brain lesions caused by either frontal, posterior, or intermediate battle wounds.

\section{Semantic knowledge}

Naming objects. We tested E. P.'s naming ability in several ways. On four separate administrations of the standard, 60-item version of the Boston Naming Test (Kaplan et al., 1983), E. P. named an average of 41.3 items correctly $(68.8 \%$; range, $65-73 \%$; four controls $=54.5$ items; $90.8 \%$ correct; range, 86.7-95.0\%; Reed and Squire, 1998). His performance improved on a four-alternative, multiple-choice version of the Boston Naming Test, but he still scored lower than controls (E. P., 93.3\%; controls, 99.7\%, range, 98.3-100\%; Reed and Squire, 1998). We also gave E. P. the same 84 -item version of the Boston Naming Test that had been given to patient H. M. E. P. scored $63 \%$ correct, H. M. scored $83 \%$ correct, and E. P.'s controls scored $87.3 \%$ correct (range, 83-91\%) (S. Corkin, personal communication; Kensinger et al., 1999).

Word and category fluency. The FAS Test asks subjects to provide as many words as possible in 1 min beginning with the letter $F$ (then A, then S; Lezak, 1976). The category fluency test asks subjects to provide as many words as possible in $1 \mathrm{~min}$ that belong to the category "animal" (then "fruits", then "vegetables"; Monsch et al., 1992). On both tests, E. P. produced fewer items than controls. On the FAS test, he produced 18 words plus four perseverative errors, whereas controls produced an average of 42 words plus two perseverative errors (range, $30-53$ words; $0-5$ perseverative errors). $\mathrm{He}$ performed better on the category test (33 words produced, 7 perseverative errors) but still scored outside the range of the controls (mean $=38.8$ words, 1.5 perseverative errors; range, 37-44, 0-4 perseverative errors).

Detecting and explaining ambiguity in sentences. E. P. was given a series of 65 ambiguous sentences (e.g., "He looked over the old stone wall"), together with 25 unambiguous sentences (Schmolck et al., 2000a). Whereas eleven controls detected correctly $78.6 \%$ of the ambiguous sentences (range, 54.0-96.9\%), E. P. was successful for only $31 \%$. Patient H. M., who was tested earlier on the same task, obtained a similar score (33.8\%; Lackner, 1974). Controls could explain spontaneously $68.5 \%$ of the ambiguous sentences (range, 35.4-87.7\%), whereas E. P. could explain 41.5\%, and H. M. could explain $37.5 \%$ (MacKay et al., 1998).

Other tests of semantic knowledge. We tested E. P. and his four controls on four tasks of semantic knowledge (for the first three tasks, see Hodges et al., 1992; Hodges and Patterson, 1995). The first test presented verbal descriptions of each of 48 items and asked participants to name the item [naming (cue: description)]. The second test presented the name of each item, together with its picture and seven other pictures from the same category. Participants were asked to point to the appropriate picture [pointing to picture (cue: name)]. The third test (semantic features) consisted 


\section{A. Personal Semantic Memory}

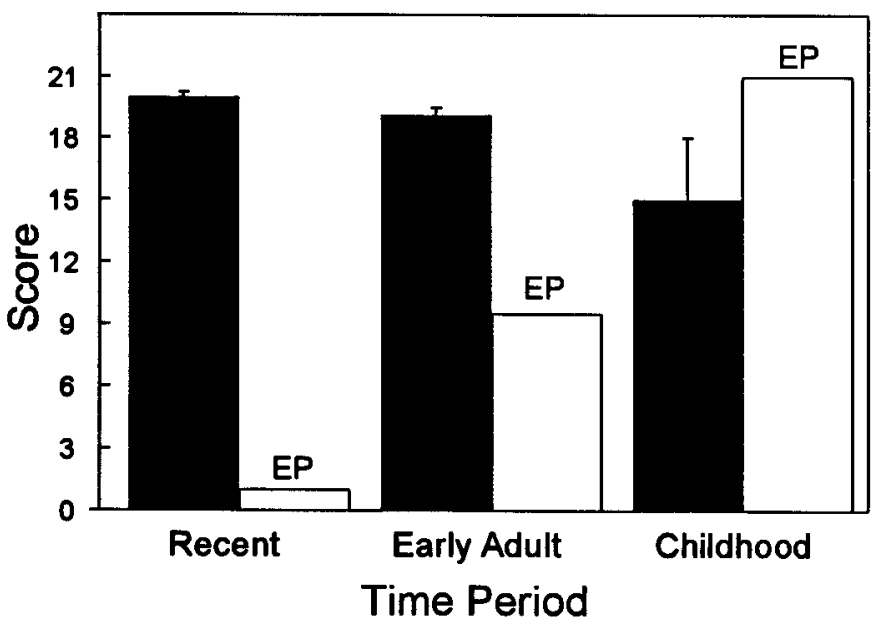

B. Autobiographical Memory

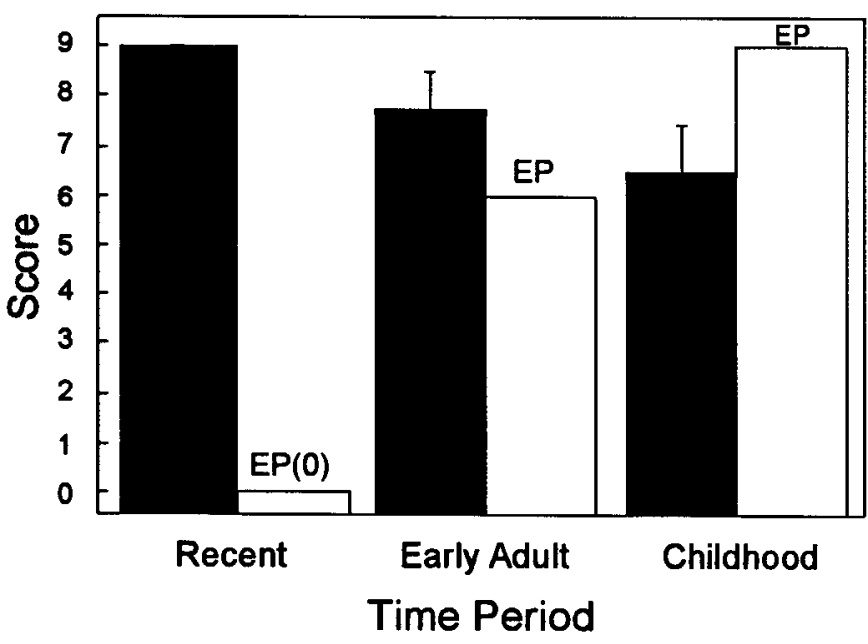

Figure 8. Performance of E. P. (open bars) and controls (black bars, $n=4$ ) on the AMI (Kopelman et al., 1989; scores from Reed and Squire, 1998). $A$, Scores for items that assessed memory for personal semantic knowledge (maximum, 21 for each time period). B, Scores for items that assessed memory for autobiographical memory (maximum, 9 for each time period). Test items associated with the recent time period assessed memory for information that could have been acquired only subsequent to the onset of his amnesia. The scores from the other two periods reflect retrograde memory function. For controls, brackets indicate the SEM.

of eight yes-no questions about each item (e.g., "Does an elephant lay eggs?"). The fourth test presented verbal descriptions of each item, together with its picture and seven other pictures from the same category, and asked participants to point to the appropriate item [pointing to picture (cue: description)]. Across all four tasks, E. P. was mildly impaired (Fig. 11). For example, on the naming task, he correctly named 37 of 48 items (control range, 42-47 items correctly named). On the pointing to picture tasks, he correctly pointed to 43 of 48 items (cue:name; control range, 47-48 items correct) and 41 of 48 items (cue:description; all controls correctly pointed to 48 items). On the semantic features task, E. P. answered all the questions correctly for six of 24 total items presented (control range, all questions answered correctly for 8-18 items).

Using other tests of semantic knowledge, we also compared E. P.'s performance to the performance of patient D. M., whose semantic dementia has been extensively documented (Breedin et al., 1994; Srinivas et al., 1997). Like E. P., D. M. has radiologically confirmed damage to the anterior inferior temporal lobes, but D. M.'s damage
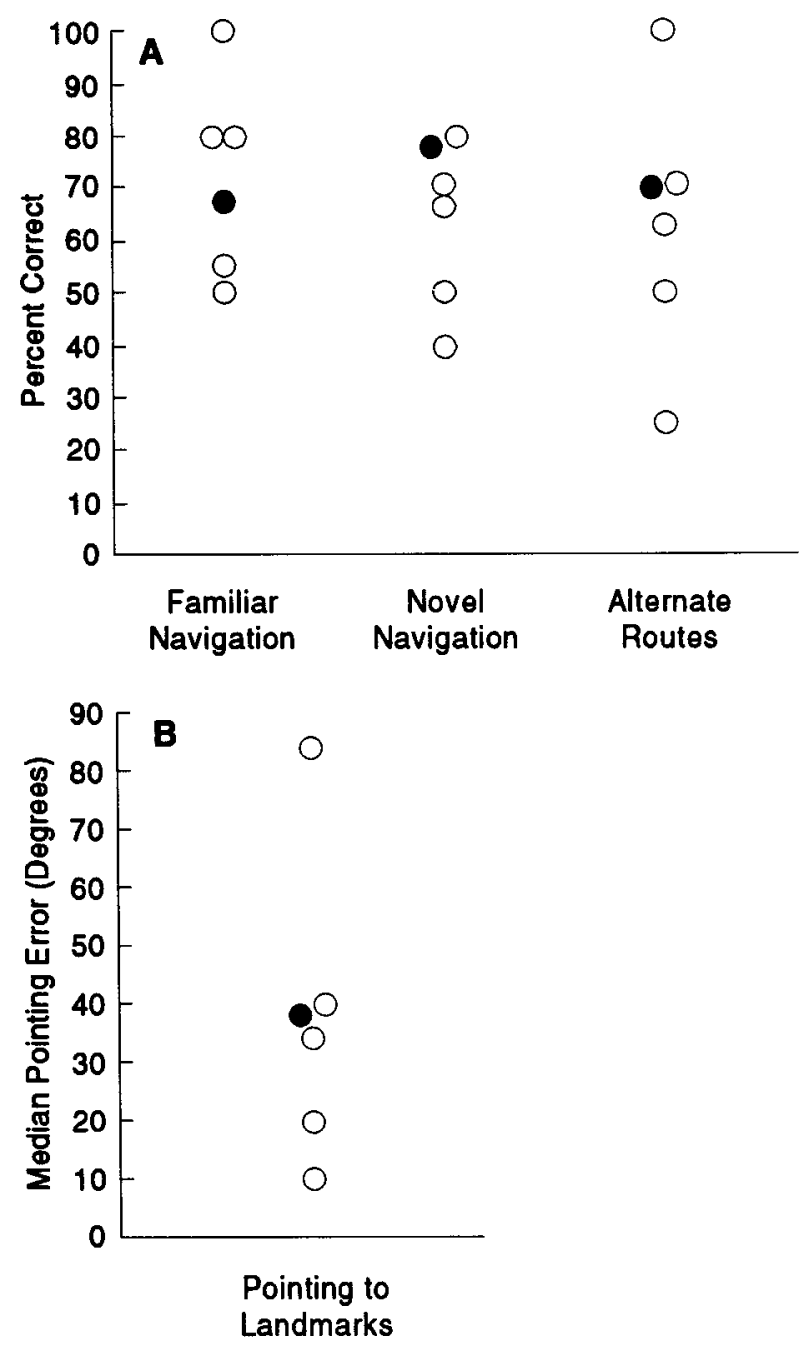

Figure 9. Performance on four tasks of topographical memory (Teng and Squire, 1999). Open circles show the scores of five control subjects. Filled circles show E. P.'s average score for two different testing sessions. $A$, Percent correct score on three verbal navigation tasks that required negotiating either familiar routes, novel routes, or alternative routes (when the most direct route was blocked). $B$, Median error in degrees on a task in which subjects pointed to particular locations while imagining themselves oriented at other locations in the neighborhood.

includes more lateral temporal cortex than is damaged in E. P. E. P. performed normally on tests that D. M. performed poorly. One task required that real objects be discriminated from nonobjects (created by combining parts of real objects, such as a violin with a duck's head; Breedin et al., 1994; Riddoch and Humphreys, 1997). E. P. made one incorrect judgment of 60 trials, for a score of $98.3 \%$ correct. (E. P.'s four controls scored 95.8\%, range, 93.3-98.3; D. M., $78.3 \%$ ). In a second task, E. P. was presented with 60 objects and asked if the objects were larger or smaller than a typical chair. E. P. scored $100 \%$ correct (control average, 99.2\%; range, 98.3$100 \%$; D. M., $78.3 \%$ ). E. P. also judged the typical weight of objects normally, scoring 96.7\% (control average, 95.8\%; range, 93.3$100 \%$; D. M., $88.3 \%$ ).

\section{DISCUSSION}

\section{Summary}

Patient E. P. has extensive, bilateral damage to the medial temporal lobe, including the amygdala, the hippocampus, the entorhinal and perirhinal cortices, and the rostral parahippocampal cortex. He also has damage to the rostral fusiform gyrus, bilaterally. In addition to these lesions, the cortical volume of the insula, lateral temporal lobes, and left parietal lobe is reduced. 


\section{A. Stem Completion}

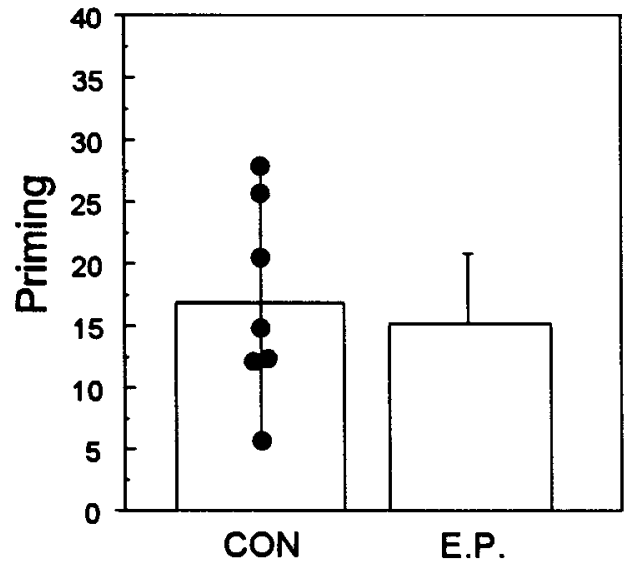

B. Perceptual Identification

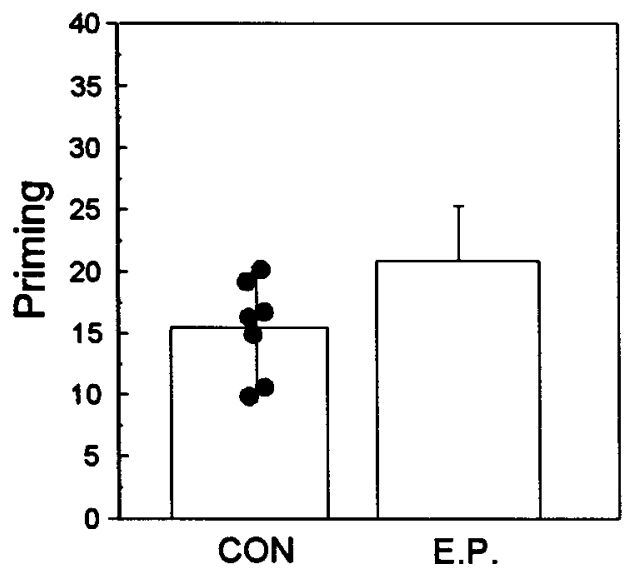

Figure 10. A, Stem-completion priming. Six tests were given to patient E. P. and normal controls $(C O N ; n=7)$. Priming scores were calculated as percent correct for studied items minus percent correct for baseline items. $B$, Perceptual identification priming. Twelve tests were given to patient E. P. and controls ( $C O N ; n=7)$. Priming scores were calculated as percent correct identification of studied items minus percent correct identification of nonstudied items. Brackets for E. P. indicate the SEM. The data points for the CON group indicate means of individual subjects across all the tests (Hamann and Squire, 1997).

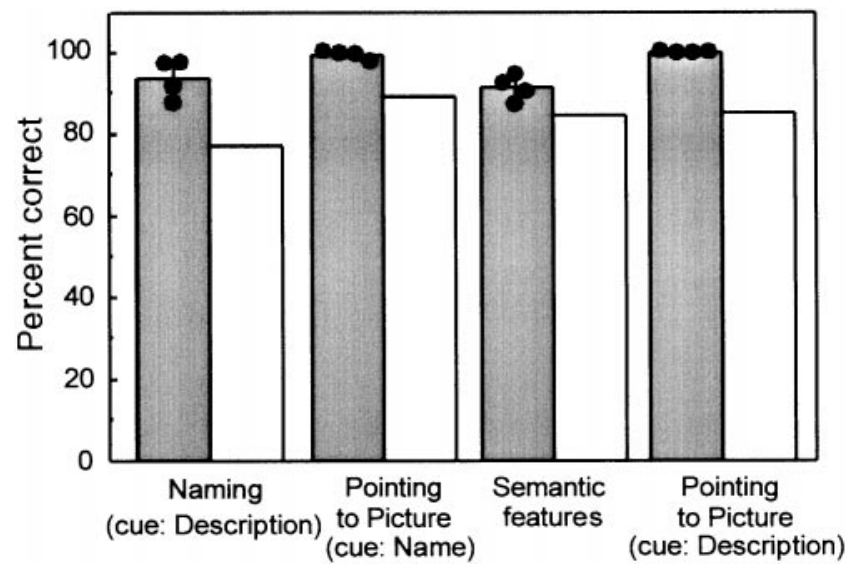

Figure 11. Performance of four control subjects (gray bars) and E. P. (open bars) on four tests of semantic knowledge. The filled circles show individual scores of the controls for each test.
Table 3. Performance on the WMS-R

E. P.

H. M.

\begin{tabular}{lrr}
\hline Verbal & 57 & 72 \\
Visual & 82 & 73 \\
General & 61 & 63 \\
Attention-concentration & 94 & 77 \\
Delay & 56 & $<50$
\end{tabular}

Scores for E. P. are from his most recent (1996) WMS-R. Scores for H. M. are from Keane et al. (1995).

E. P. has normal or near-normal intellectual functions as measured by standard tests. His immediate memory and nondeclarative memory are intact. In contrast, he has profound anterograde amnesia and is impaired on a wide variety of verbal and nonverbal tests of recall and recognition. He also has severe and extensive retrograde amnesia for facts and events, personal semantic knowledge, and autobiographical memory, but he appears fully capable of retrieving memories acquired in his early life, including detailed spatial memories of his childhood neighborhood. Finally, he is mildly impaired on tests of semantic knowledge, including tests of object naming, tests involving the detection and explanation of ambiguous sentences, and tests that asked about the features of common objects.

\section{Comparison with patient H. M.}

Damage to the medial temporal lobe

Corkin et al. (1997) recently described H. M.'s surgical lesion in considerable detail using MRI. These findings, compared with the findings for E. P. presented here, indicate that E. P.'s medial temporal lobe lesion is more extensive than H. M.'s, particularly with regard to the perirhinal cortex, the parahippocampal cortex, and hippocampus (Fig. 1).

With respect to the perirhinal cortex, E. P. sustained complete damage bilaterally, whereas H. M. has some sparing of its ventrocaudal aspect. With respect to the parahippocampal cortex, the damage in E. P. includes the rostral $18 \%$ on the left side and the rostral $57 \%$ on the right side, whereas this region is almost completely spared bilaterally in $\mathrm{H}$. M. With respect to the hippocampus, we identified in E. P. a tag of severely atrophic tissue within the temporal horn of the lateral ventricle bilaterally, and the volume of this tissue remnant is $\sim 10 \%$ of the average volume of the hippocampus of control brains. In H. M., the posterior portion of the hippocampus ( $\sim 50 \%$ of the normal intraventricular extent) is present, although the tissue appears to be "somewhat atrophic bilaterally" (Corkin et al., 1997, page 3976). Both patients sustained similar (i.e., virtually complete) damage to the entorhinal cortex and the amygdaloid complex.

At the level of the rostral hippocampus, E. P.'s temporal white matter damage may invade a portion of his temporal stem. The "temporal stem" hypothesis of medial temporal lobe amnesia (Horel, 1978) proposes that bilateral temporal stem damage is crucial to memory impairment. However, it is unlikely that the minor damage to this massive fiber bundle present in E. P. is sufficient to produce the devastating amnesic syndrome that we have observed. Moreover, patient H. M. has profound amnesia, but H. M. has no temporal stem damage (Corkin et al., 1997). Thus, the findings from E. P. and H. M. provide no support for the temporal stem hypothesis of medial temporal lobe amnesia.

\section{Damage outside of the medial temporal lobe}

In the temporal lobe, E. P.'s lesion extends laterally to involve the fusiform gyrus, bilaterally. In addition, there is some cortical volume loss in the inferior, middle, and superior temporal gyri, particularly on the right side. H. M.'s lesion does not involve the fusiform gyrus, but there is damage at the temporal pole that involves the middle and superior temporal gyri (Fig. 1; also see Corkin et al., 1997, their Figs. $2 K, 4 C, D$, pages 3967 and 3970). 
In addition, in H. M. "the subcortical white matter associated with the anterior portions of the superior, middle, and inferior temporal gyri may also have been compromised by the resection" (page 3975).

There is also some cortical volume loss in E. P.'s insula and left parietal lobe. Whereas Corkin et al. (1997) did not perform volumetric measurements of H. M.'s cortex, they did compare his brain with an age-matched control brain and reported slight neocortical atrophy in H. M. that was judged to be consistent with his age. Finally, H. M. has marked atrophy of his cerebellum (vermis and hemispheres) that is not present in E. P.

\section{Neuropsychology}

In many ways, E. P. and H. M. have strikingly similar neuropsychological profiles. They have similar intellectual function (E. P.'s full scale WAIS-R IQ, 103; H. M.'s WAIS-R IQ in 1997, 101; Corkin, personal communication). They also have comparable scores on the information and vocabulary subtests of the WAIS-R (E. P., 17 and 33, respectively; in 1997 H. M. scored 18 and 39, respectively; Corkin, personal communication). They both perform normally on tests of immediate memory (for H. M., see Keane et al., 1995). Additionally, both patients have intact nondeclarative memory, as measured by perceptual priming tasks (for H. M., word-stem completion, Gabrieli et al., 1994; perceptual identification, Keane et al., 1995), and skill learning tasks (for H. M., Parsons et al., 1988). The fact that E. P. and H. M. perform normally on a wide range of cognitive tasks is consistent with the circumscribed nature of their brain lesions, which in both cases are largely restricted to the medial temporal lobe.

Both E. P. and H. M. have profoundly impaired anterograde memory (Table 3). Nevertheless, on tests of recognition memory that used the same procedures, H. M. benefited from extended study time (Freed et al., 1987), whereas E. P. did not (Reed et al., 1997). E. P. has more extensive medial temporal lobe damage than H. M., and this more extensive damage may account for E. P.'s poorer anterograde memory performance on these tests.

With regard to retrograde memory, E. P. and $\mathrm{H}$. M. both have access to early memories. E. P.'s retrograde amnesia covers $\sim 40-50$ years before the onset of his encephalitis. Whereas H. M.'s retrograde amnesia has been described as covering only 11 years before his surgery (Corkin, 1984), 11 years of retrograde amnesia would for H. M. extend back to age 16. Note that E. P., who became amnesic at the age of 70, can also retrieve memories from before the age of 16 (Reed and Squire, 1998; Teng and Squire, 1999). Perhaps if H. M. had become amnesic in middle age, he also would have exhibited more extensive retrograde amnesia.

E. P. is mildly but unequivocally impaired on some tests of semantic knowledge, including tests of object naming and tests involving the detection and explanation of ambiguous sentences. H. M. is also impaired on tests of ambiguous sentences (Lackner, 1974; MacKay et al., 1998), but his naming ability (which falls within $1 \mathrm{SD}$ of the mean of his control group tested at MIT), is superior to E. P.'s (Corkin, personal communication; Kensinger et al., 1999). What damage might account for E. P.'s impairment in semantic knowledge? We suggest that damage to the lateral temporal lobes, and in particular damage to the fusiform gyrus, is responsible for E. P.'s impairment. Damage to anterior lateral inferotemporal cortex, including the fusiform gyrus, has been reported to produce the kinds of semantic deficits that we observed in E. P. (Hodges et al., 1992; Garrard et al., 1997; Srinivas et al., 1997). Note also that patient D. M., and other patients with extensive lateral temporal lobe damage, perform more poorly than E. P. on tests of semantic knowledge. Finally, the idea that the fusiform gyrus itself is important for semantic knowledge is supported by imaging studies demonstrating activation of the fusiform gyrus during object naming and during other tasks that depend on semantic knowledge (Moore et al., 1996; Vandenberghe et al., 1996; Henry et al., 1998; Moore and Price, 1999).

H. M. does not have damage to the fusiform gyrus and is better than E. P. at confrontational naming. H. M. does, however, have difficulty with ambiguous sentences, which could be attributable to the damage he has to the lateral aspect of the temporal pole. Yet, H. M. also exhibits difficulties on language tests that E. P. does not exhibit (Schmolck et al., 2000a,b). For example, on a test that asked patients to provide definitions of common items, H. M. exhibited many grammatical and linguistic errors, whereas E. P. and other patients with more extensive medial and lateral temporal lobe damage performed like controls. It is also true that H. M.'s seizures began at age 10 , and his education was interrupted at age 16 (he received a high school diploma at age 21). Accordingly, it is possible that $\mathrm{H}$. M. did not develop fully normal language abilities. In any case, his language shortcomings appear to be unrelated to his temporal lobe pathology.

In summary, E. P. has profound and relatively circumscribed amnesia as the result of viral encephalitis that damaged his medial temporal lobe, bilaterally. There are striking similarities between E. P. and the surgical patient H. M., both with respect to the neuroanatomy of their lesions and their cognitive neuropsychological profiles. For more than 40 years, neuropsychological studies of memory have depended crucially on the ideas and the findings derived from a single, well studied patient (H. M.). E. P. provides a second example, based on a different etiology, of profound memory impairment after medial temporal lobe damage. The detailed neuroanatomical and neuropsychological information obtained from E. P. is useful in three respects. First, the findings from E. P. largely confirm what has been learned from H. M. about the importance of the medial temporal lobe for memory. Second, E. P.'s difficulties on some tests of semantic knowledge suggest the importance of lateral temporal cortex, including the fusiform gyrus, for performance on these tests. Third, it has been difficult to know which features of H. M.'s performance are central to his memory impairment and which features are unrelated. The findings from E. P. suggest that H. M.'s difficulties with language expression are unrelated either to his memory impairment or his temporal lobe pathology.

\section{REFERENCES}

Amaral DG, Insausti R (1990) Hippocampal formation. In: The human nervous system, (Paxinos G, ed). San Diego: Academic.

Anderson SW, Damasio H, Jones RD, Tranel D (1991) Wisconsin cardsorting test performance as a measure of frontal lobe damage. J Clin Exp Neuropsychol 13:909-922.

Baddeley AD, Warrington EK (1970) Amnesia and the distinction between long- and short-term memory. J Verb Learning Verb Behav 9:176-189.

Baddeley AD, Wilson BA, Watts FN (1995) Handbook of memory disorders. Chichester, NY: Wiley.

Breedin SD, Saffran EM, Coslett HB (1994) Reversal of the concreteness effect in a patient with semantic dementia. Cognit Neuropsychol 11:617-660.

Buffalo EA, Reber PJ, Squire LR (1998) The human perirhinal cortex and recognition memory. Hippocampus 8:330-339.

Butters N, Cermak L (1980) Alcoholic Korsakoff's syndrome. An information processing approach to amnesia. New York: Academic.

Cave CB, Squire LR (1992) Intact verbal and nonverbal short-term memory following damage to the human hippocampus. Hippocampus 2:151-163.

Cermak LS (1976) The encoding capacity of a patient with amnesia due to encephalitis. Neuropsychologia 14:311-326.

Corkin S (1984) Lasting consequences of bilateral medial temporal lobectomy: clinical course and experimental findings in H. M. Semin Neurol $4: 249-259$.

Corkin S, Amaral DG, Gonzalez RG, Johnson KA, Hyman BT (1997) H. M.'s medial temporal lobe lesion: findings from magnetic resonance imaging. J Neurosci 17:3964-3979.

Cox RW (1996) AFNI: software for analysis and visualization of functional magnetic resonance neuroimages. Comput Biomed Res 29:162-173.

Damasio AR, Eslinger PJ, Damasio H, Van Hoesen GW (1985) Multimodal amnesic syndrome following bilateral temporal and basal forebrain damage. Arch Neurol 42:252-259.

Freed DM, Corkin S, Cohen NJ (1987) Forgetting in H. M.: a second look. Neuropsychologia 25:461-471.

Gabrieli JDE, Keane MM, Stanger BZ, Kjelgaard MM, Corkin S, Growdon JH (1994) Dissociations among structural-perceptual, lexical-semantic, and event-fact memory systems in Alzheimer, amnesic, and normal subjects. Cortex 30:75-103. 
Garrard P, Perry R, Hodges JR (1997) Disorders of semantic memory. J Neurol Neurosurg Psychiatry 62:431-435.

Hamann SB, Squire LR (1997) Intact perceptual memory in the absence of conscious memory. Behav Neurosci 111:850-854.

Hamann SB, Cahill L, Squire LR (1997) Emotional perception and memory in amnesia. Neuropsychology 11:104-113.

Henry TR, Buchtel HA, Koeppe RA, Pennell PB, Kluin KJ, Minoshima S (1998) Absence of normal activation of the left anterior fusiform gyrus during naming in left temporal lobe epilepsy. Neurology 50:787-790.

Hodges JR, Patterson K (1995) Is semantic memory consistently impaired early in the course of Alzheimer's disease? Neuroanatomical and diagnostic implications. Neuropsychologia 33:441-459.

Hodges JR, Salmon DP, Butters N (1992) Semantic memory impairment in Alzheimer's disease: failure of access or degraded knowledge? Neuropsychologia 30:301-314.

Horel JA (1978) The neuroanatomy of amnesia. A critique of the hippocampal memory hypothesis. Brain 101:403-445.

Janowsky JS, Shimamura AP, Kritchevsky M, Squire LR (1989) Cognitive impairment following frontal lobe damage and its relevance to human amnesia. Behav Neurosci 103:548-560.

Kaplan EF, Goodglass H, Weintraub S (1983) The Boston naming test. Philadelphia: Lea and Febiger.

Keane MM, Gabrieli JDE, Mapstone HC, Johnson KA, Corkin S (1995) Double dissociation of memory capacities after bilateral occipital-lobe or medial temporal-lobe lesions. Brain 188:1129-1148.

Kensinger EA, Ullman MT, Locasio JJ, Corkin S (1999) What is the relation between medial temporal lobe structures and lexical memory? Evidence from amnesic patient H.M. Soc Neurosci Abstr 25:357.

Kopelman MD, Wilson BA, Baddeley AD (1989) The autobiographical memory interview: a new assessment of autobiographical and personal semantic memory in amnesic patients. J Clin Exp Neuropsychol 5:724-744.

Lackner JR (1974) Observations on the speech processing capabilities of an amnesic patient: several aspects of H. M.'s language function. Neuropsychologia 12:199-207.

Lezak MD (1976) Neuropsychological assessment. New York: Oxford UP.

MacKay DG, Stewart R, Burke DM (1998) H. M. revisited: relations between language comprehension, memory, and the hippocampal system. J Cognit Neurosci 10:377-394.

Mattis S (1976) Dementia rating scale. In: Geriatric psychiatry 1 (Bellack R, Karasu B, eds), pp 77-121. New York: Grune and Stratton.

Mayes (1988) Human organic memory disorders. Cambridge: Cambridge UP.

Milner B, Squire LR, Kandel ER (1998) Cognitive neuroscience and the study of memory. Neuron 20:445-468.

Monsch AU, Bondi MW, Butters N, Salmon DP, Katzman R, Thal LJ (1992) Comparisons of verbal fluency tasks in the detection of dementia of the Alzheimer type. Arch Neurol 49:1253-1258.

Moore CJ, Price CJ (1999) Three distinct ventral occipitotemporal regions for reading and object naming. NeuroImage 10:181-192.

Moore CJ, Price CJ, Friston KJ, Frackowiak RSJ (1996) Phonological retrieval and semantic processing during naming tasks. Paper presented at Second International Conference on Functional Imaging of the $\mathrm{Hu}$ man Brain, Boston, June.

Osterrieth PA (1944) Le test de copie d'une figure complexe [The test of copying a complex figure]. Archives de Psychologie 30:206-356.
Parsons LM, Gabrieli JDE, Yucaitis J, Corkin S (1988) Normal improvement in mental rotation skill in global amnesia. Soc Neurosci Abstr 14:1290.

Press GA, Amaral DG, Squire LR (1989) Hippocampal abnormalities in amnesic patients revealed by high-resolution magnetic resonance imaging. Nature 341:54-57.

Rapaport D (1942) Emotions and memory. Baltimore: Williams and Wilkins.

Reber PJ, Squire LR (1998) Encapsulation of implicit and explicit memory in sequence learning. J Cognit Neurosci 10:248-263.

Reed JM, Squire LR (1998) Retrograde amnesia for facts and events: Findings from four new cases. J Neurosci 18:3943-3954.

Reed JM, Hamann SB, Stefanacci L, Squire LR (1997) When amnesic patients perform well on recognition memory tests. Behav Neurosci 111:1163-1170.

Rempel-Clower N, Zola SM, Squire LR, Amaral DG (1996) Three cases of enduring memory impairment after bilateral damage limited to the hippocampal formation. J Neurosci 16:5233-5255.

Ribot T (1881) Les maladies de la memoire [Diseases of memory]. New York: Appleton-Century-Crofts.

Riddoch MJ, Humphreys GW (1997) Visual object processing in optic aphasia: a case of semantic access agnosia. Cognit Neuropsychol 4:131-185.

Schmolck H, Stefanacci L, Squire LR (2000a) Detection and explanation of sentence ambiguity are unaffected by hippocampal lesions but are impaired by larger temporal lobe lesions. Hippocampus, in press.

Schmolck H, Stefanacci L, Kensinger L, Corkin S, Squire LR (2000b) Semantic memory in patient H. M. and other patients with bilateral medial and lateral temporal lobe lesions. Soc Neurosci Abstr, in press.

Scoville WB, Milner B (1957) Loss of recent memory after bilateral hippocampal lesions. J Neurol Neurosurg Psychiatr 20:11-21.

Squire LR, Knowlton BJ (1995) Learning about categories in the absence of memory. Proc Natl Acad Sci USA 92:12470-12474.

Squire LR, Shimamura AP (1986) Characterizing amnesic patients for neurobehavioral study. Behav Neurosci 100:866-877.

Srinivas K, Breedin SD, Coslett HB, Saffran EM (1997) Intact perceptual priming in a patient with damage to the anterior inferior temporal lobes. J Cognit Neurosci 9:490-511.

Stark CEL, Squire LR (2000) Chance recognition memory performance in severe amnesia: no evidence for the use of repetition priming in familiarity judgments. Behav Neurosci 114:459-467.

Talland G (1965) Deranged memory. New York: Academic.

Teng E, Squire LR (1999) Memory for places learned long ago is intact after hippocampal damage. Nature 400:675-677.

Teuber H-L, Battersby WS, Bender MB (1951) Performance of complex visual tasks after cerebral lesions. J Nerv Ment Dis 14:413-429.

Vandenberghe R, Price C, Wise R, Josephs O, Frackowiak RSJ (1996) Functional anatomy of a common semantic system for words and pictures. Nature 383:254-256.

Warrington EK (1984) Recognition memory test. Windsor, England: FER-Nelson.

Warrington EK, McCarthy RA (1988) The fractionation of retrograde amnesia. Brain Cogn 7:184-200.

Winslow F (1861) On obscure diseases of the brain and disorders of the mind, Ed 2. London: John W. Davies. 